\title{
Los palacios de Themis
}

Si todos estuviéramos en la cárcel durante doso tres generaciones, el mundo entero, finalmente, seharía mucho mejor... J. B. Finley, Cincinnati, I85I

E N el Ámbito de la convulsionada Primera República Central ${ }^{\mathrm{I}}$ (I837-184I) bajo el gobierno del general Anastasio Bustamante transcurría el otoño de i840: el D epartamento de Texas se hallaba irremediablemente perdido y el de Yucatán separado de la Unión. Aunque en la ciudad de M éxico se vivía una tensa calma, Valentín Gómez Farías y José U rrea preparaban un nuevo golpe de Estado, con la intensión de restaurar el federalismo.

A consecuencia de la publicación de la carta en donde José M aría Gutiérrez Estrada proponía que la única forma de contener el inminente desmembramiento del país era mediante el restablecimiento de la monarquía, ${ }^{2}$ el autor tuvo que salir hacia un segundo exilio europeo, del que ya no regresaría jamás, y el editor I gnacio Cumplido fue remitido el 23 de octubre a la Cárcel Nacional de la ex Acordada. ${ }^{3}$

I. Josefina Zoraida Vázquez, "Los primeros tropiezos", en Daniel Cosío Villegas, H istoria general de M éxico, M éxico, El Colegio de M éxico, I98I, vol. 2, pp. 763-764.

2. Enrique Cárdenas de la Peña, M il personajes en el M éxico del siglo XIX, I840-I870, M éxico, Banca Somex, 1979, vol. 2, p. I67.

3. Ignacio Cumplido, "La cárcel de la Acordada en M éxico. O rigen de esta prisión, y su estado moral en la actualidad", en EI M osaico M exicano o colección de amenidades curiosas e instructivas, M éxico, I84I, t. v, I23-I34, pp. I26-I27. 


\section{I44}

HUGO ARCINIEGA

Era un tiempo de escarmientos definitivos: los ciudadanos que, valiéndose de la letra impresa, cuestionaban el régimen en turno, sabían que podían ir a parar a una terrible cárcel en donde las condiciones imperantes pondrían su vida en peligro. De estos procedimientos silenciatorios dieron cuenta desde Cumplido, en la ex Acordada, hasta los hermanos Flores M agón, en Belén. En el primer caso, la oportunísima intervención de amigos acaudalados salvó a Cumplido de los horrores esperables. A su ingreso fue alojado en una de las antiguas viviendas de los funcionarios virreinales, en donde, además de alimentarse bien, podía recibir visitas. ${ }^{4}$ Tratamiento especial que no era raro para quien pudiera hacer un generoso desembolso a favor del alcaide mayor.

A I gnacio Cumplido se le presentó, entonces, la oportunidad de emprender uno de los viajes más apreciados por la mentalidad ilustrada del siglo xix: al mundo de los delincuentes. 5 Situándose, convenientemente, en el extremo opuesto al de la "degradación de la especie humana" y enunciando una actitud totalmente "científica" se dispusieron, no sin un dejo de repugnancia, a establecer, con sus "filantrópicos ojos", una tipologización de la monstruosidad social. Las cárceles se convirtieron, junto con los jardines botánicos, las casas de fieras, los hospitales y las fábricas, en laboratorios para la observación, estudio y transformación de la conducta; ${ }^{6}$ constituyéndose, además, en parámetros confiables para cuantificar el nivel de "progreso" alcanzado por una nación.

Cumplido encontró en la Cárcel $\mathrm{N}$ acional todo lo que esperaría hallar un conocedor de los grabados de Piranesi7 y de las obras de John $\mathrm{H}_{\text {oward }}{ }^{8}$ y del doctor Gall:" una enorme masa de hombres sucios, "ladrones, asesinos, raptores, canalla de toda especie y vagabundos de toda clase", ro infestados de

4. Ibidem.

5. M ichel Foucault, Vigilar y castigar. Nacimiento de la prisión, M éxico, Siglo XXI, 1989, p. 256 .

6. M assimo Pavarini, "La invención penitenciaria: la experiencia de los Estados U nidos de América en la primera mitad del siglo xIx", en D ario M elossi, Cárcel y fábrica. Los orígenes del sistema penitenciario (siglos XVI-XIX), M éxico, Siglo XXI, I980, p. I93.

7. John Summerson, El lenguaje clásico de la arquitectura. De L. B. Alberti a Le Corbusier, Barcelona, Gustavo Gili, 1984, p. I24.

8. The State of the Prisionsin England and W ales... , I777-I784.

9. Cumplido, op. cit., p. I29.

ı. Brantz M ayer, M éxico: lo que fue y lo que es, M éxico, Fondo de Cultura Económica, 1953, p. 353 . 
parásitos y apenas vestidos de andrajos, se aglomeraban en el patio principal. "Algunos se dedicaban a bañarse y restregarse en la fuente; otros a pelearse en un rincón; los de allá [fabricaban] cestas, acá se [había] reunido un grupo en torno de un hábil narrador que [contaba] las aventuras de su vida [... ] otro grupo [trabajaba] en un telar de mano." "I Los más débiles eran hostilizados, de tiempo en tiempo, por los "presidentes o jefes de los calabozos", curtidos malhechores renombrados por su fiereza y por despojar de toda pertenencia a los recién ingresados.

Los calabozos eran angostas crujías, oscuras, mal ventiladas, los pisos cubiertos de petates y los muros con la sangre que legiones de chinches extraían a los presos. El hambre apenas era mitigada con pan, atole, frijoles y arroz de sabor tan terrible, que para poderlos comer, algunos lavaban los granos con el agua turbia de la fuente. Una ausencia total de disciplina y de cualquier intención reformadora permitía que las bebidas embriagantes, los naipes y las armas de fuego circularan libremente entre una población que ocupaba las horas maquinando planes de evasión o dirigiendo, desde el encierro, al resto de la banda que permanecía libre cometiendo todo tipo de atropellos. ${ }^{12}$

Apenas logró quedar en libertad (el 24 de noviembre de I840) y ya como editor de la revista EI M osaico M exicano, Cumplido tomó la pluma para sumarse a la literatura que describía esos cuadros de espanto: cárceles, calabozos, grilletes, tormentosy "el penoso estado moral de los condenados". Profundamente impresionado ante un idealizado sistema penitenciario norteamericano, ${ }^{13}$ llegó a concluir: "A vista de lo que pasa en la cárcel de la Acordada a mediados del siglo xix ¿qué diferencia se encuentra con lo que acontecía en el siglo xvi, dentro de las cárceles de Europa, cuando los progresos de la civilización tenían respecto de hoy, el atraso de más de doscientos años?" I4

La Cárcel $\mathrm{N}$ acional de la ex Acordada representaba una herencia del pasado colonial que debía ser superada por el Estado mexicano. Luego de obtener su libertad, hombres y mujeres profundamente resentidos por el trato allí recibido se volverían contra la sociedad con más encono que antes, por lo que se hacía ya impostergable edificar una prisión "más apropiada a la conve-

II. Ibidem.

I2. Cumplido, op. cit., p. I34.

13. Especialmente con las penitenciarías de Cherry-H ill en Pensilvania y Sing-Sing en N ueva York.

I4. Cumplido, op. cit., p. I3o. 
DOI: http://dx.doi.org/10.22201/iie.18703062e.2000.76.1895

146

HUGO ARCINIEGA

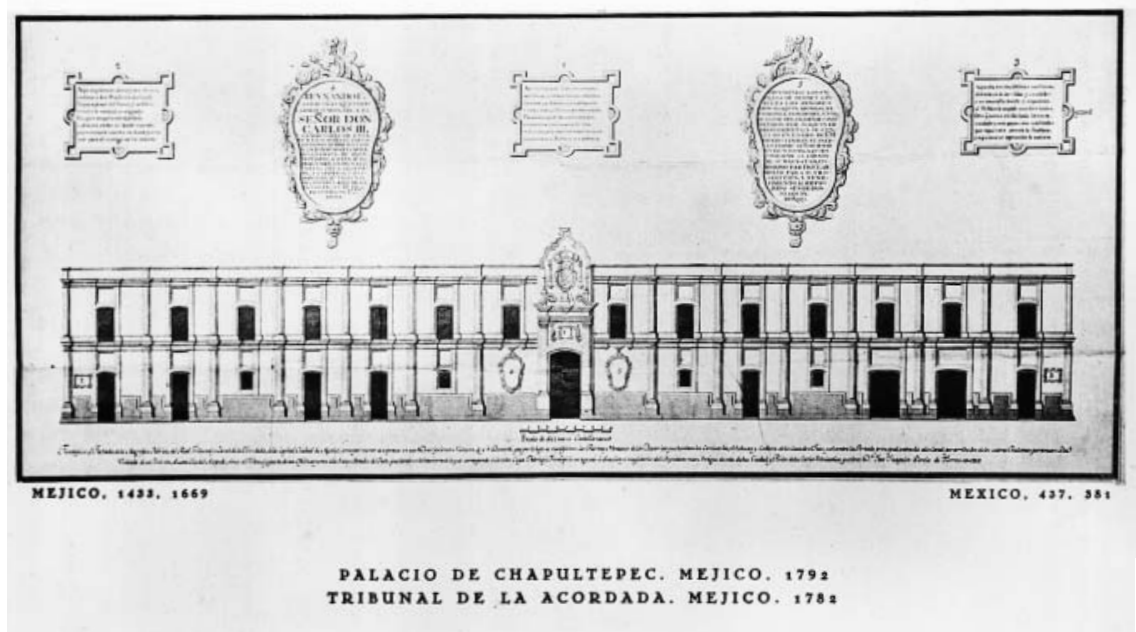

Figura i. Real Tribunal y cárcel de la A cordada, fachada norte, maestro de arquitectura J osé J oaquín G arcía de Torres, 1777. Foto: H ugo Arciniega (H A).

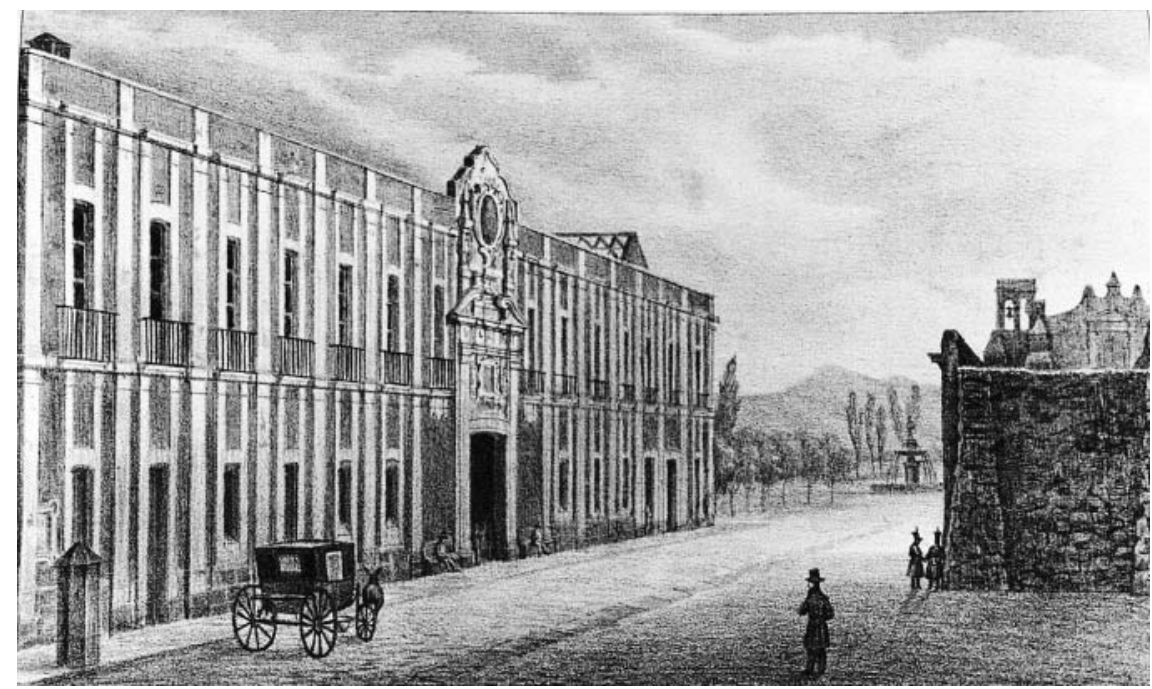

Figura 2. Cárcel Nacional de la ex Acordada, calzada y capilla del Calvario en I84I. Ignacio Cumplido, El M osaico M exicano. Foto: H A. 
niencia de un país en el camino del progreso, más acomodada al estado de la civilización". ${ }^{\text {. }}$

Los objetivos de esta investigación son, en primer lugar, analizar la evolución de un género edilicio, en este caso la prisión, a través de la comparación de dos edificios, con igual función pero diseñados en diferentes momentos históricos, para identificar cómo se manifiestan en los espacios urbano-arquitectónicos los cambios en la mentalidad de las clases rectoras y cómo es transformada y finalmente desechada una obra arquitectónica por una sociedad determinada.

El último periodo barroco de la sociedad virreinal quedará expresado en la cárcel de la Acordada; y los primeros veintisiete años de vida independiente, en el proyecto de penitenciaría de Lorenzo de la H idalga. Elegí una cárcel y una penitenciaría porque considero que se cuentan entre los programas arquitectónicos en donde más claramente se manifiesta la actitud que el Estado guarda hacia sus ciudadanos.

En segundo lugar, documentar un hito en el largo proceso que inició, en $1824,{ }^{16}$ con el proyecto de Vicente Rocafuerte para construir un molino movido por la fuerza de los presos, y concluyó, en i90o, con la inauguración de la penitenciaría de Lecumberri. Proceso de cambio en la forma de castigar al individuo que atenta contra el grupo social.

\section{Los delincuentes-obreros}

I gnacio Cumplido no se limitó a denunciar, ante sus suscriptores, las condiciones de la $\mathrm{C}$ árcel $\mathrm{N}$ acional sino que adelantó un proyecto para su transformación. Según sus artículos, I7 la penitenciaría debía ser una "escuela reformadora" a donde ingresarían los individuos que la misma sociedad había orillado a delinquir y que ahora se encargaría también de corregir, mediante el trabajo en común en grandes talleres textiles (que bien podrían quedar a cargo de empresarios particulares), y mediante la soledad nocturna y el silen-

I5. Ibidem, p. I34.

I6. N ydia E. C ruz Barrera, "Reclusión, control social y ciencia penitenciaria en Puebla en el siglo xix", en Siglo xıx. Revista de H istoria, M éxico, julio-diciembre de I992, núm. I2, p. I27.

I7. Ignacio Cumplido, "La cárcel de la Acordada en M éxico. M odelos para una reforma", en El M osaico M exicano... , M éxico, I84I, t. v, pp. I45-153. 


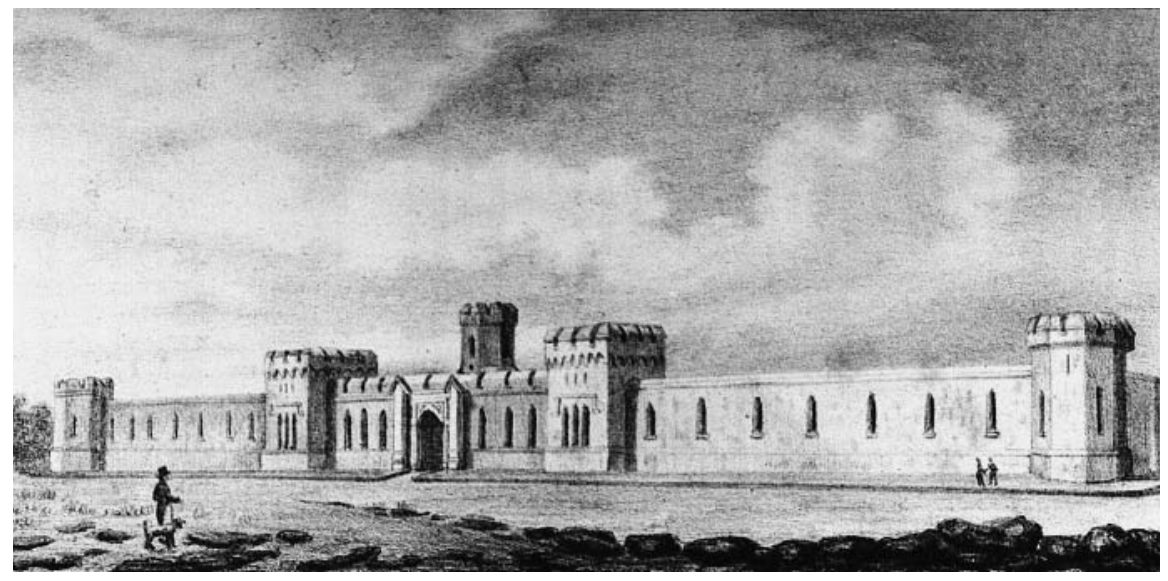

Figura 3. Penitenciaría de Cherry-H ill en Filadelfia. Ignacio Cumplido, El M osaico M exicano. Foto: HA.

cio permanente. D e esta manera se les enseñaría una nueva "moral", oficios para ganarse la vida de un modo "decente" y una total obediencia a la "gente de razón". Al finalizar la condena se obtendrían ciudadanos sumisos, obreros potenciales y buenos padres de familia. ${ }^{18}$

Por medio de Cherry-H ill y de Sing-Sing, Cumplido conoció las experiencias norteamericanas y su objetivo de formar mano de obra calificada para la planta industrial privada, ${ }^{19}$ y también mediante la penitenciaría de Madrid, proyectada por el arquitecto Aníbal Álvarez, la aplicación del sistema de vigilancia centralizada o panóptico de Jeremy Bentham. ${ }^{20}$

I8. "se entrega a la dulce esperanza de ser al gún día hombre honrado, centro de una familia feliz, que sostendrá y educará, ejerciendo la profesión que en su cautiverio ha aprendido y las máximas de sana moral que le han enseñado [... ] al volver estos presos a la sociedad, hallarían como por encanto corregida su moral, y se encontrarían convertidos en artesanos útiles, en buenos padres de familia. De otro modo, ¿de qué servirá propagar la educación primaria e inculcar al niño en la escuela las mejores máximas, si cuando regresa diariamente a la casa, se halla en los que le dieron el ser un ejemplo constante de los crímenes más vergonzosos..." Cumplido, op. cit., pp. I50-i7i.

I9. "Estados U nidos del N orte [... ] una nación tan vecina a la nuestra, no creo que debamos ir más lejos a buscar modelos cuando los tenemos casi a nuestras puertas [... ] admirables establecimientos, en que el ingenio humano ha sabido conciliar la reforma moral del delincuente, con sus comodidades personales y la economía de su mantenimiento... " I bidem, p. I46. 
Fue Cumplido quien propuso la construcción de una penitenciaría celular con capacidad para i 600 hombres y 400 mujeres; que contaría con talleres, enfermerías y cocinas; todo rodeado por un muro perimetral. Se pronunció contra el estilo neogótico aplicado en Cherry-H ill y sugirió una severa austeridad que consideraba más adecuada para el destino del inmueble. El emplazamiento más conveniente sería, en su opinión, el ejido de la H orca, al surponiente de la capital. Fascinado con el ejemplo de Elam Lynds en Sing-Sing, los propios reos se encargarían de levantar los muros de sus celdas. El financiamiento provendría de la deuda que la hacienda pública mantenía con el ayuntamiento de M éxico y de la venta de los ejidos de San Lázaro, San Antonio Abad y otras propiedades de la ciudad.

Si bien es cierto que para el inicio de las obras tendrían que transcurrir ocho años más, lo es también que los artículos de Cumplido reavivaron el interés por las condiciones de los reclusos entre la minoría instruida; así José M aría Castera, M ariano Gálvez, Juan N epomuceno V értiz y Luis 0 ctavio C housal establecieron una escuela lancasteriana en la ex Acordada. ${ }^{2 I}$

Luego de algunos meses la $\mathrm{C}$ árcel $\mathrm{N}$ acional se vio envuelta en un nuevo escándalo: hasta la comisión del ramo llegó una denuncia en contra de Pedro $M$ eneses. D icho alcaide acostumbraba sacar a pasear a las presas de su agrado; mantenía relaciones con ellas y organizaba bailes en el departamento femenino. Su acusador, José Sámano, era un "presidente de calabozo" resentido al ya no poder monopolizar la venta de aguardiente en el presidio. ${ }^{22}$

En tanto que el inglés Frederick Catherwood visitaba el país, por segunda vez, para registrar la arquitectura maya, un contratista radicado en la capital llamado Santiago Condon viajaba por los estados de Pennsylvania, N ueva York y Connecticut recorriendo las penitenciarías de Filadelfia, Auburn y Sing-Sing, levantando sus plantas arquitectónicas, copiando sus reglamentos, evaluando los progresos de la reforma criminal y analizando sus presupuestos, que ya no dependían totalmente de los erarios públicos. Además de inte-

20. "conseguir que todos los presos pudieran ver un objeto colocado en el centro, sin que pudieran verse entre sí. Este problema lo ha resuelto satisfactoriamente el Sr. Álvarez." Cumplido, op. cit., p. is2.

2I. José M aría Castera, "La cárcel de la Acordada en M éxico. Establecimiento de una escuela en esta prisión", en El M osaico M exicano..., M éxico, I84I, t. v, p. 216.

22. José Sámano, carta al Sr. prefecto del Centro, 3 de agosto de I842, Archivo $\mathrm{H}$ istórico del ex Ayuntamiento de la ciudad de M éxico (АНЕACM), cárceles en general, V. 497, exp. 2I2, ff. I-2. 
grar un informe, ahora perdido, en I843 presentó al M inisterio de Relaciones Exteriores e Interiores de $M$ éxico un proyecto para construir una penitenciaría con capacidad para mil presos, totalmente inspirada en la de Sing-Sing, que costaría \$347 815.20 pesos. ${ }^{23}$

Para Condon la ex Acordada resultaba "una caverna inmunda" que los "amantes de la humanidad" no podían permitir. En tanto que en sus calabozos se reproducían conductas que atentaban contra "la persona y propiedades de los habitantes pacíficos", nada justificaba que el ayuntamiento de la capital distrajera $\$ 60$ ooo.oo pesos anuales de sus menguadas arcas para alimentar a esos seres "ociosos" que además de todo conspiraban contra la sociedad. Se debía ponerlos a trabajar, en talleres textiles, para que cubrieran sus gastos y los sueldos del personal de vigilancia; así al finalizar la condena quedarían capacitados para ingresar directamente a la fábrica.

En una época en la cual el arquitecto, para construir, tenía que promover personalmente sus proyectos ante el Estado, convencer de su imperiosa necesidad y presentar alternativas para obtener recursos financieros, Condon proponía gravar, durante dos años, a todas las mercancías que, por las garitas, entraran en la ciudad. El ayuntamiento aportaría el terreno, preferentemente al norte, y él se encargaría, durante seis meses, de preparar al nuevo personal que pondría por obra la reforma penitenciaria. Sin detenerse en dar explicaciones, el cabildo rechazó la propuesta.

\section{La reforma moral en dos dimensiones}

La guerra con los Estados U nidos pospuso, por al gún tiempo, las reformas al sistema carcelario del país; pero una vez firmado el Tratado de Paz, Amistad y Límites, en Guadalupe H idalgo el 2 de febrero de i848, la ciudad de M éxico se vio presa de otra de sus cíclicas crisis de seguridad pública. De esto dio cuenta el periódico El Siglo Diez y N ueve:

la capital se halla plagada de malhechores de todos calibres, de vagos y mal entretenidos, que en todas direcciones y a todas horas atacan a los ciudadanos pacíficos y los despojan de cuanto pueden, ya con notorias violencias, ya con

23. Santiago Condon, sobre que se construya en esta capital una cárcel penitenciaría, 27 de junio de i843, АНЕАСм, cárceles en general, v. 497, exp. 217, ff. I-9. 
ardides y engaños [... ] teniendo presente que la seguridad pública es de las primeras exigencias que se deben satisfacer... ${ }^{24}$

Se repite una visión de la población urbana que establecía tres tipos de habitante: "el malhechor, el vago y el ciudadano pacífico". Los dos primeros, "necesariamente", provenían de los estratos sociales menos favorecidos, en donde la ociosidad, la ignorancia, la necesidad extrema y los efectos del pulque se sumaban a "instintos perversos inherentes" conduciendo al pobre 0 al indígena por una única senda que, desde un estadio intermedio de "vagancia", derivaría irremediablemente en la práctica criminal. Los terceros eran los instruidos o los propietarios industriosos, que pugnaban por el sometimiento, transformación y control de esas "clases peligrosas" para mudarlas en dóciles trabajadores, respetuosos de la nueva jerarquía social y de la propiedad individual. ${ }^{25}$

La frecuente impunidad de los infractores de la ley ponía en entredicho el poder del Estado y socavaba el proyecto de Nación "integrada, ordenada y jerarquizada" que abrazaban por igual liberales y conservadores. ${ }^{26}$

Cuatro factores se conjuntaron, entonces, para concretar el proyecto de la penitenciaría:

Primero. La necesidad de incorporar a la producción a una numerosa población pobre que, se creía, representaba un peligro potencial para los intereses de una emergente burguesía.

Segundo. La llegada a la presidencia de la República del general José Joaquín $\mathrm{H}$ errera, ${ }^{27}$ resuelto a restablecer el orden en ciudades y caminos, así como a mejorar el sistema penitenciario. ${ }^{28}$

Tercero. El nombramiento, como ministro de Relaciones Exteriores e Interiores, del jurista M ariano 0 tero, ${ }^{29}$ amplio conocedor de las obras de H oward y Bentham y uno de los creadores del juicio de amparo. ${ }^{30}$

24. J. M . G., "Seguridad pública", en El Siglo D iez y N ueve, M éxico, Io de junio de i848, p. 2.

25. Salvador Rueda Smithers, El diablo de Semana Santa. El discurso político y el orden social en la ciudad de M éxico en I850, M éxico, Instituto N acional de Antropología e H istoria, I99I, p. 69.

26. I bidem, p. 47.

27. Del 3 de junio de 1848 al 8 de enero de 185 I.

28. Lilia Díaz, "El liberalismo militante", en Daniel Cosío Villegas, Historia general de M é xico, op. cit., vol. 2, p. 82I.

29. Del ${ }_{4}$ de junio al ${ }_{4}$ de noviembre de 1848 .

3o. Cárdenas, op. cit., p. 697. 
DOI: http://dx.doi.org/10.22201/iie.18703062e.2000.76.1895

152

HUGO ARCINIEGA

C uarto. La campaña emprendida desde una poderosa prensa en contra de la Cárcel $\mathrm{N}$ acional de la ex Acordada. ${ }^{31}$

Argumentando desde un marco referencial integrado por los principios de razón, justicia, caridad y salubridad pública, los editorialistas cuestionaron el grado de hacinamiento que se había alcanzado en la Cárcel $\mathrm{N}$ acional, ${ }^{32}$ y calificaron de "bárbaro e inhumano" a un sistema que sólo privaba de la libertad y no revertía los "sentimientos de venganza" que se alojaban entre los procesados; 33 censuraron la costumbre de reunir en un mismo espacio a detenidos y procesados con la consiguiente "contaminación" de los primeros por los segundos, 34 y denunciaron una ya escandalosa falta de vigilancia. 35

Como funcionario de un Estado débil, $\mathrm{M}$ ariano 0 tero sabía que la estabilidad del gobierno dependía, en buena medida, de su capacidad de negociación con las élites y con la prensa. ${ }^{36}$ Así que se dispuso a "civilizar y moralizar" a los "sujetos de control" mediante la modernización del sistema penitenciario:37 primero estableció una Junta Inspectora de Cárceles, en la que invitó a participar a José M aría Lacunza, Guillermo Prieto, $M$ anuel Payno y José M aría I glesias. ${ }^{38}$ Luego envió al Congreso de la Unión una iniciativa de ley para la "adopción y establecimiento del régimen penitenciario en el D istrito Federal y Territorios". 39 U na vez aprobada ésta, $4^{40}$ convocó a un concurso de proyectos para edificar la penitenciaría de la capital. ${ }^{4 \mathrm{I}}$

\section{I. Específicamente El Siglo Diez y N ueve.}

32. "Se hallan en un recinto muy estrecho, donde ni aun la respiración puede verificarse sin la mayor violencia. Aun en pie los reos no caben sino estrechados unos con otros. Sentados todos casi es imposible que puedan estar, y acostados sólo podrían hacinados unos sobre otros... " J. M. G., "M uy importante”, en El Siglo Diez y N ueve, M éxico, Io de julio de i848, remitidos, p. 4.

33. Ibidem.

34. "Cárceles", en El Siglo Diez y N ueve, M éxico, is de julio de i848, pp. 3-4.

35. Ibidem.

36. Fernando Escalante Gonzalbo, Ciudadanos imaginarios, M éxico, El Colegio de M éxico, I998, p. I24.

37. Rueda, op. cit., pp. 93-94.

38. "Junta Inspectora de Cárceles", en El Siglo Diez y N ueve, M éxico, 22 de julio de i848, p. 4.

39. M ariano $O$ tero, "Iniciativa dirigida a la Cámara de D iputados por el ministro de Relaciones, sobre la adopción y establecimiento del régimen penitenciario en el $\mathrm{D}$ istrito y T erritorios", en El Siglo Diez y N ueve, M éxico, in de agosto de i848, pp. I-2.

40. El decreto fue publicado el lunes 9 de octubre de 1848 .

4I. M ariano O tero, "Convocatoria", en El Siglo Diez y Nueve, M éxico, ro de octubre de I848, p. I. 
H asta que se modificó la estructura legal del país fue cuando se materializó la posibilidad de construir el nuevo edificio que sería sólo un componente del sistema integrado por "una casa de corrección para jóvenes delincuentes, un presidio, un asilo para los reos que hubieran cumplido ya su condena y un hospital"; 42 inmuebles que sustituirían a los de la ex Acordada, cárcel de la Diputación y ex convento de Santiago T latelolco. La nueva obra se aprobó debido a que resultaba prácticamente imposible reutilizar cualquier edificio novohispano para implantarle el sistema de vigilancia centralizada o panóptico:

No es posible, como alguna vez se ha propuesto, convertir ningún edificio ya existente en penitenciaría, en razón de que el plano de éstas es absolutamente diverso de los edificios que pudieran pensarse en reformar; y de que este género de construcciones es bastante caro, si han de hacerse con todas las condiciones que exige la seguridad y absoluta incomunicación de los reos... 43

El 7 de octubre de i848 el propio ministro de Relaciones firmó la convocatoria del concurso. Se pedía un edificio panóptico en donde privara el sistema de reclusión celular de Filadelfia; ${ }^{44}$ con una capacidad de 500 a 600 celdas ${ }^{45}$ distribuidas en dos niveles, de los cuales 40 deberían ser de mayor tamaño para alojar notables. Cada celda contendría su propia instalación sanitaria; sería calentada artificialmente en invierno y ventilada en verano a través del sistema cruzado. El programa partiría de una sala de inspección central que, los domingos, debería convertirse en capilla, e incluiría la casa para el director y sus asistentes, salones para ocho juzgados, dos locutorios, cocinas, áreas de lavado de ropa, almacenes, una sala de operaciones quirúrgicas y prados en los que los reclusos pudieran ejercitarse en completo aislamiento; todo rodeado por un muro perimetral. Se recomendaba austeridad y severidad en el ornato: sólo el acceso principal quedaría custodiado por las estatuas de Jeremy Bentham y John H oward como homenaje permanente a sus aportaciones.

42. O tero, "I niciativa... ", en El Siglo Diez y N ueve, op. cit., pp. I-2.

43. Ibidem.

44. “4a. Las celdas estarán construidas de modo que desde un punto central puedan verse todas; y como desde ellas han de asistir los presos a la ceremonia de la misa... " O tero, "C onvocatoria", en El Siglo Diez y N ueve, op. cit., p. I.

45. "de una manera de que los presos vivan y trabajen en sus celdas sin reunirse jamás para acto alguno..." I bidem. 
Debido a que aún se mantenía el recuerdo del Pronunciamiento de la Acordada ${ }^{46}$ se pedía al diseñador, quizá la parte más compleja, que sin descuidar una óptima seguridad ante posibles evasiones colectivas, se evitara edificar una plaza fuerte en donde al guna facción rebelde pudiera atrincherarse en un futuro.

Los concursantes tenían prácticamente un mes para desarrollar los planos;47 el jurado quedaría integrado por 0 tero y dos profesores de la Academia de San Carlos. H abría un premio único de $\$ 600.00$ pesos para el arquitecto vencedor.

El inexistente capital indispensable para emprender las obras provendría de cinco confusas partidas: los fondos que la hacienda pública adeudaba a la Cárcel Nacional; la deuda que el gobierno de la República mantenía con el ayuntamiento de la capital; los sobrantes de la lotería de la Academia de San Carlos; ${ }^{8}$ los fondos piadosos que, literalmente, se pudiese atrapar y el $4 \%$ de todas las contribuciones que se cobrasen en la ciudad de M éxico y demás territorios.

Varias consideraciones pueden extraerse de esta convocatoria: en primer lugar sorprende que 0 tero propusiera el aislamiento total o sistema Filadelfia, 49 ya en pleno desuso en Estados U nidos y en Europa, ${ }^{50}$ debido a que los procesos de producción industrial de la época implicaban la participación de grupos de trabajadores y no la labor solitaria en el interior de una celda, que sólo podría reproducir el sistema artesanal. Es evidente la traslación casi literal que 0 tero hace del Panopticón de Jeremy Bentham en una época en que las experiencias norteamericanas hacían su aplicación más flexible y propositiva. Sus paradigmas, John H oward y Jeremy Bentham, habían publicado las obras clásicas en i777 y ı79i; y de entonces a

46. El 30 de noviembre de 1828 .

47. Del 7 de octubre al io de noviembre de i848.

48. "Segundo. T odos los productos de la lotería de San Carlos cubiertos [... ] los sueldos de los empleados en la oficina, los gastos del sorteo, los de la Academia de Bellas Artes y el pago de los premios atrasados... " O tero, "Iniciativa... ", en El Siglo Diez y N ueve, op. cit., pp. I-2.

49. "Ias acusaciones en contra del sistema penitenciario vigente, que a través de la realización del solitary confinment no sólo privaba al mercado de la fuerza de trabajo, sino que también con la imposición de un trabajo antieconómico deformaba a los internados, reduciendo en ellos la capacidad de trabajo que ya tenían... " Pavarini, op. cit., p. I7I.

5o. "el segundo congreso penitenciario de 1847 - en Francia — opta contra este método de aislamiento absoluto... " Foucault, op. cit., p. 240. 
I848 mucho se había discutido sobre el particular. Al comparar los requerimientos de la convocatoria con los proyectos desarrollados por Cumplido y Condon, los segundos resultaban más congruentes con los tiempos que corrían.

Existe, sin embargo, un tratado que probablemente consultaron los tres utopistas: La Architectonographie des prisons, de Víctor Baltard. ${ }^{\text {.I }}$ Las dos propuestas antes señaladas subrayaban, igual que Baltard, la austeridad en el ornato y la economía en la edificación, en razón de que la seguridad se obtendría mediante una vigilancia permanente y no por la altura y grosor de las paredes.

El proyecto se tambalea cuando 0 tero renuncia al ministerio; 52 no obstante, desde la Junta D irectiva de Cárceles, de la que pasa a formar parte, propone al Ayuntamiento aplicar el panopticón, también, al diseño de un nuevo hospital municipal.53

Los convocantes recibieron una docena de proyectos, de los que resultó elegido el firmado con el lema "Paralelo y proyecto de penitenciaría", ${ }^{54}$ que amparaba al arquitecto español Lorenzo de la H idalga y M usitu. Para entonces, éste contaba con 38 años de vida, de los cuales los últimos diez había residido en $\mathrm{M}$ éxico.

D e la $\mathrm{H}$ idalga era una figura prominente dentro de la sociedad mexicana con un sólido prestigio profesional, que le habían conferido obras de la magnitud del nuevo mercado en la plaza del Volador, en i84i; el Gran Teatro Santa Anna y las reformas en el edificio del Apartado $\mathrm{N}$ acional del $\mathrm{O}$ ro y la Plata, en i843; la reedificación del colegio de San Gregorio y la reposición de la cúpula de la capilla del Señor de Santa Teresa, en i845. Estos edificios iniciaron la transformación del perfil novohispano que todavía ofrecía la ciudad de M éxico. En sí mismo abarcó dos épocas: por un lado detentaba el honroso cargo de "Arquitecto de la Santa Iglesia Catedral" y por el otro era

5I. V íctor Baltard, La Architectonographie des prisons ou parallèle des di vers systèmes de distribution dont les prisons sont susceptibles, París, Víctor Baltard, i829. Un ejemplar de esta obra se conserva en el Fondo Reservado de la Biblioteca $\mathrm{N}$ acional de $\mathrm{M}$ éxico, proveniente de la antigua Academia de San C arlos.

52. Lo sustituye en el cargo Luis G. C uevas.

53. M ariano O tero, "H ospitales", en El Siglo Diez y Nueve, M éxico, 20 de noviembre de I848, p. 4 .

54. "Planos para penitenciarías", en El Siglo D iez y N ueve, M éxico, 6 de diciembre de 1848 , p. 4. 
DOI: http://dx.doi.org/10.22201/iie.18703062e.2000.76.1895

156

HUGO ARCINIEGA

miembro del Real Instituto de Arquitectos Británicos y había sido profesor en el Colegio M ilitar. 55

D urante 1848 había recibido varios encargos del ayuntamiento de M éxico: en abril se le pidió que formara un presupuesto para reedificar el $\mathrm{C}$ ementerio de Santa Paula; ${ }^{6}$ en mayo, que planeara, en sociedad con el ingeniero Francisco de Garay, un nuevo canal para evitar las periódicas inundaciones de la capital. ${ }^{57}$ Por su parte el cabildo catedralicio discutía con él sobre la mejor ubicación del nuevo ciprés que también había proyectado..$^{8}$

D e la H idalga era, también, una personalidad controversial: en I843 tuvo que hacer frente a las desfavorables críticas que mereció la proporción empleada en el segundo nivel del mercado del Volador; 59 en agosto del mismo año Enrique Griffon ganó el concurso de un monumento a los héroes de la Independencia, pero finalmente, y sin dar muchas explicaciones, la obra le fue encomendada al arquitecto vasco. ${ }^{60}$ En lo referente a la penitenciaría la decisión del jurado fue impugnada por un mal perdedor que sólo firmaba con el lema: "la verdadera libertad consiste en el ejercicio de la justicia". ${ }^{6 r}$ Sin exponer sus razones, objetaba en el proyecto ganador su mala distribución y lo calificaba como demasiado costoso y caduco. ${ }^{62}$

El conjunto de dibujos remitidos por los otros concursantes fue exhibido con bastante retraso en la Primera Exposición Anual de la Academia de San Carlos; compartiendo créditos con las obras de M anuel Vilar, Felipe Sojo, Santiago Rebull, I. J. Bagali, Ángela I caza, Josefa Sanromán y M ercedes Spada. Para la prensa no había en los once proyectos rechazados nada de extraordinario:

55. Elisa García Barragán, "El palacio de Lecumberri y su contexto arquitectónico", en Patricia Galeana, Lecumberri: U n palacio Ileno de historia, M éxico, Secretaría de G obernaciónArchivo General de la N ación, 1994, p. 45.

56. "Panteón de Santa Paula", en El Siglo Diez y Nueve, M éxico, 25 de octubre de I848, p. 4.

57. "N uevo canal", en El Siglo Diez y N ueve, M éxico, is de diciembre de i848, p. I.

58. "Compostura de la Catedral", en El Siglo Diez y N ueve, M éxico, 22 de octubre de ı848, p. 4 .

59. Elisa G arcía Barragán, “Lorenzo de la H idalga”, en Santiago Sebastián, D el arte. H ome naje a Justino Fernández, M éxico, Universidad N acional Autónoma de M éxico, Instituto de Investigaciones Estéticas, 1977, p. 216.

6o. I bidem, p. 206.

6r. "Penitenciarías", en El Siglo Diez y N ueve, M éxico, i9 de diciembre de I848, p. 4.

62. El Siglo Diez y N ueve, M éxico, i3 de diciembre de i848, remitidos, p. 3. 
en la escuela de arquitectura no vemos, en verdad, cosa que llame la atención, y francamente creemos que podrían los profesores haber puesto un poco más de esmero para que ese ramo estuviera en relación con los adelantos que se notan en los demás diversos planos de penitenciarías, hechos a consecuencia de la convocatoria, que están a la vista, extrañándose solamente el que obtuvo el premio, y que ha llegado por accidente a nuestra noticia, que es de un discípulo del Sr. H idalga: como están colocados los planos de la penitenciaría en muy incómodos lugares, y sea necesario examinarlos detenidamente, no podemos aventurar ninguna opinión. D e lo que se puede formar juicio a primera vista, que es de las fachadas, francamente diremos que no hay una sola que nos agrade... ${ }^{63}$

Las identidades de los arquitectos contendientes no se dieron a conocer pues, una vez elegido el ganador, los sobres sellados que contenían esos datos fueron quemados. ${ }^{64} \mathrm{D}$ e la $\mathrm{H}$ idalga no contestó, a través de la prensa, a los inconformes y, por instrucciones de la Junta de Cárceles, se abocó a recorrer algunos parajes vecinos a la capital para elegir el emplazamiento de su nueva obra. ${ }^{65}$

O tra nota anónima, en el periódico, sólo firmada como "uno de los opositores", decía: "ya recibiremos a los 400 50 años un edificio en ruinas para seguir dando a nuestro pueblo la educación de unos viles esclavos... " 66

\section{Del calabozo al sistema celular}

¿Cómo eran los dos edificios, el rechazado, la casa y cárceles de hombres y mujeres del Real Tribunal de la Acordada y, el aprobado, la Penitenciaría Ge neral de la ciudad de M éxico? N inguno de los dos existe en el presente y sólo nos podemos aproximar a ellos a través de los planos del primero, conservados en el Archivo de Indias en Sevilla, ${ }^{67}$ y los del segundo publicados por Ignacio

63. "Academia de San Carlos. Exposición I848", en El Siglo Diez y N ueve, M éxico, 28 de diciembre de 1848, p. 3.

64. O tero, "C onvocatoria", en El Siglo Diez y N ueve, op. cit., p. I.

65. "Penitenciarías", en El Siglo Diez y N ueve, M éxico, 20 de diciembre de 1848, p. 4.

66. EI Siglo Diez y N ueve, M éxico, 26 de diciembre de i848, remitidos, p. 2.

67. D iego Angulo Íñiguez, Planos de monumentos arquitectónicos de América y Filipinas exis tentes en el Archivo de Indias. Estudio de los planos y de su documentación, España, U niversidad de Sevilla, 1939, vol. I, de láminas. 


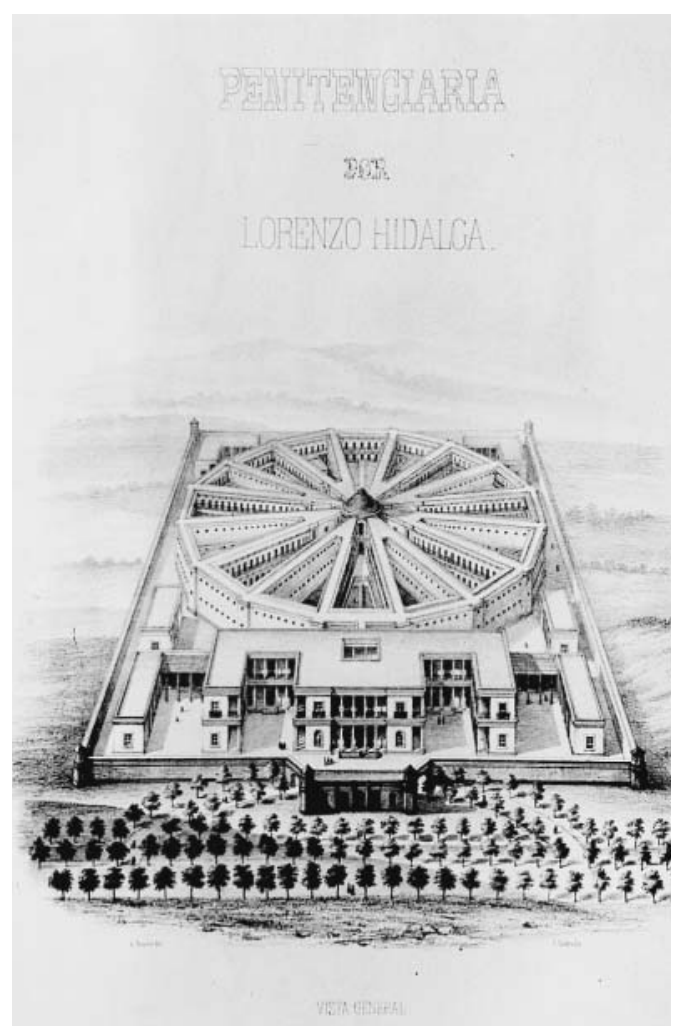

Figura 4. Penitenciaría General de la ciudad de M éxico, arquitecto Lorenzo de la H idalga, I85o. M apoteca M anuel O rozco y Berra, Secretaría de Agricultura, G anadería y D esarrollo Rural.

Cumplido en $1850 .{ }^{68}$ Litografías, fotografías y descripciones nos completan la visión del inmueble novohispano; del republicano, sólo lo poco que los arquitectos Ramón Rodríguez Arangoiti y Emilio D ondé dejaron registrado en sus respectivas bitácoras cuando, años más tarde, intentaron reutilizar el predio en donde aquél apenas desplantaba un poco más arriba de los cimientos. ${ }^{69}$

68. Lorenzo de la Hidalga, Paralelo y proyecto de penitenciaría aprobado por la Junta de Cárceles, M éxico, Ignacio C umplido, I850, portada.

69. H ugo Antonio Arciniega Ávila, "EI xix, otro siglo de utopías", en G ladys Sirvent Gutiérrez, Colonia Tabacalera: varias lecturas sobre un patrimonio, M éxico, U niversidad Autónoma M etropolitana-Xochimilco, 1994, pp. 38-88. 


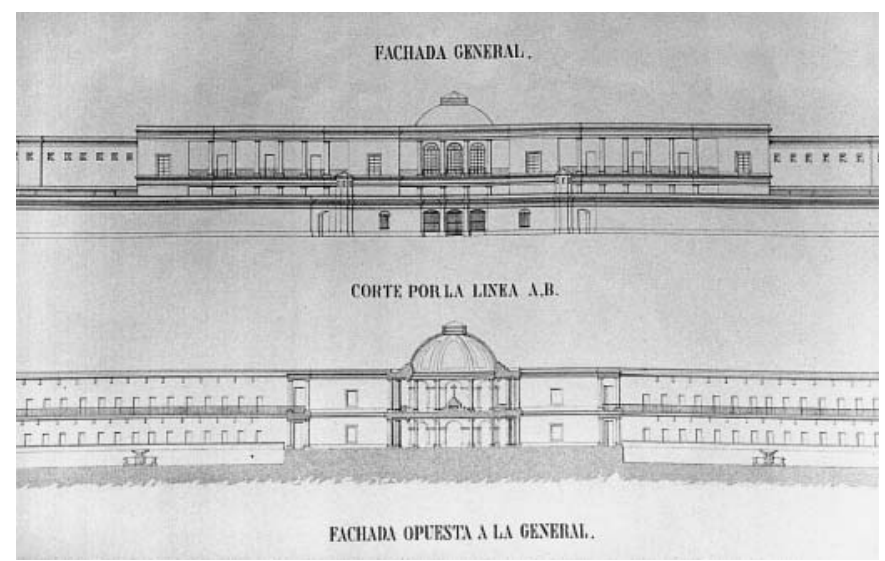

Figura 5. Penitenciaría G eneral de la ciudad de M éxico, fachada norte y corte $A-B$, arquitecto Lorenzo de la H idalga, I85o. M apoteca M anuel O rozco y Berra, Secretaría de Agricultura, G anadería y D esarrollo Rural.

\section{Los arquitectos}

En tanto que los autores alcanzaron la misma posición jerárquica dentro de sus respectivas sociedades, procede la comparación de las obras. José Joaquín García de Torres también obtuvo el título de académico de mérito por la entonces Real Academia de San C arlos; proyectó para la C atedral y el Palacio Virreinal. Además del edificio de la Acordada, el veedor de arquitectura nos dejó las portadas del convento de San Lorenzo de M éxico. ${ }^{\circ}$

\section{La ubicación}

El primer edificio que alojó al Tribunal y Cárceles de la Acordada se edificó, en $1757,{ }^{71}$ al surponiente de la ciudad de M éxico, en una fracción de los terrenos que, desde el siglo xvi, eran propiedad del ayuntamiento; destinados, por ordenanza, a satisfacer las futuras necesidades de expansión y en tanto la mancha urbana tocó sus límites, se arrendaron a particulares para pastoreo y

70. G uillermo Tovar de T eresa, Repertorio de artistas en M éxico. Artes plásticas y decorativas, Singapur, Espejo de 0 bsidiana, I996, t. II, pp. 46-47.

7I. El tribunal se fundó, años antes, entre i710 y 1715. 
cultivo. ${ }^{72}$ Con el nombre de Ejido de Concha se conocía el predio cedido, que demarcaban al norte la calzada del Calvario; al sur, la calle de la V ictoria; al oriente, la calle de la Acordada y, al poniente, los ejidos de la $\mathrm{H}$ orca. ${ }^{73}$

Frente a su acceso principal estaba la capilla del Calvario, última de las estaciones procesionales que, partiendo del Convento Grande de San Francisco, conmemoraban la pasión y muerte de Jesucristo. No me parece accidental que unos metros adelante quedara el lugar de las ejecuciones capitales, 74 y que uno de los quemaderos de la Inquisición hubiera funcionado frente a la iglesia de San D iego. D espués de todo, según la tradición popular, el poniente es el lugar de los muertos.

Los cultos asociados con el arrepentimiento de los ajusticiados residían en torno a la Alameda: el Señor de la M isericordia, cuya hermandad acompañaba a los mal hechores hasta el cadalso, en la Santa Vera Cruz,75 y la virgen de la Soledad, en la capilla del C alvario.

El sismo del 21 de abril de 1776 afectó a tal punto este primer edificio que hubo que demolerlo y levantar otro en el mismo sitio: el proyectado por García de Torres. ${ }^{76}$ Este hecho nos podría indicar que la lectura del espacio urbano no había variado en diecinueve años.

En el caso de la penitenciaría, De la H idalga proyectó sin haber elegido un lugar específico para levantarla. ${ }^{77} \mathrm{M}$ ás tarde, el ayuntamiento de la capital decidió cederle una generosa porción en los ejidos de la $\mathrm{H}$ orca, un emplazamiento previamente sugerido por Ignacio Cumplido atendiendo a: "su saludable temperamento; estar rodeado de hermosa vegetación"; quedar a conveniente distancia de la antigua fábrica de tabacos, entonces cuartel; la facilidad para derivar agua de los dos acueductos y la posibilidad de aprovechar el río que corría a un costado del Cementerio Inglés para desfogar las aguas

72. Arciniega, op. cit., p. 39.

73. Corresponde en la actualidad: al norte, con la avenida Juárez; al sur, con la calle de la Victoria; al oriente, con la de Lucas Balderas; y al poniente, con Agustín de Iturbide. Las calles de $\mathrm{H}$ umboldt y $\mathrm{D}$ onato Guerra se abrieron posteriormente, fraccionando el predio original. Antonio García Cubas, El libro de mis recuerdos... , M éxico, Porrúa, 1986, p. 229.

74. En la intersección de avenida de la República con Rosales.

75. M anuel Rivera Cambas, M éxico pintoresco, artístico y monumental... , M éxico, Ediciones del V alle de M éxico, 1974, t. I, p. 249.

76. El edificio se comenzó el iz de octubre de i777 y se finalizó el 20 de enero de i78I. Angulo, op. cit., vol. I, pp. I50-152.

77. "Penitenciarías", en El Siglo Diez y N ueve, M éxico, 20 de diciembre de i848, p. 4. 
negras. ${ }^{78}$ Es claro que en esta decisión ya están presentes las políticas higienistas generadas, a finales del siglo xviII, en las ciudades francesas, 79 y que demandaban un suelo firme, libre de inundaciones y con buena ventilación. El lote designado daba frente hacia la calzada del Ejido, y por seguridad se tuvieron que crear dos nuevas vialidades perpendiculares a ésta, primero la de Penitenciaría y posteriormente la de Los Inválidos, ${ }^{80}$ que por oriente y poniente limitarían el conjunto de nuevos edificios.

Fecha de los proyectos e inicio de la construcción

El edificio de la cárcel se inició el i3 de octubre de 1777 y fue concluido el 20 de enero de ${ }_{1781:{ }^{81}}$ cuatro años de trabajos hasta su inauguración. La penitenciaría fue proyectada en i848, en i853 se iniciaron los trabajos que, con largas interrupciones, se prolongaron hasta 1862, cuando se decidió suspenderlos definitivamente. Catorce años para levantar poco más que los cimientos. Entre el trazado de ambos programas corre una distancia temporal de setenta y dos años y el tránsito de la administración virreinal a la republicana.

\section{Los promotores}

Los más interesados en volver a levantar la cárcel de la Acordada fueron los comerciantes de la N ueva España, quienes sufrían cuantiosas pérdidas en mercancías y caudales a manos de los salteadores de caminos; así que el Tribunal del Consulado de la ciudad de M éxico aportó los \$ I9i ooo.oo pesos que costó el nuevo edificio. ${ }^{82}$ En el caso de la penitenciaría, en una primera lectura, se podría decir que se debe a 0 tero, durante el tiempo en que estuvo al frente del ministerio de Relaciones Interiores y Exteriores. En realidad el

78. I gnacio C umplido, "La cárcel de la Acordada en M éxico. Posibilidad de su reforma", en El M osaico M exicano... , M éxico, I84I, t. v, p. I72.

79. Foucault, op. cit., pp. I4-I5; y M ichele Perrot, "El inspector Bentham", en Jeremy Bentham, El panóptico, M éxico, Premiá, 1989, p. 165.

8o. Ejido es avenida de la República; Penitenciaría corresponde a Lafragua, e Inválidos a Vallarta.

8i. Angulo, op. cit., vol. I, pp. I50-152.

82. I bidem, p. 327. 
jurisperito tapatío recogió las repetidas propuestas provenientes de una minoría enterada, preocupada por la integridad de sus personas y fortunas; inconforme con el rezago existente ante los sistemas carcelarios de Estados Unidos y Europa y que buscaba aprovechar, en beneficio propio, la fuerza de trabajo que se desperdiciaba en la reclusión. En ambos casos el Estado sólo sirvió de medio, ya que correspondió a las clases altas impulsar dichas obras.

\section{Losusuarios}

Luego de su fundación, el Tribunal de la Acordada no necesitó de calabozos debido a que el corto proceso que seguía a la detención de los infractores terminaba con su inmediata ejecución, sobre las mismas rutas asoladas por los ladrones. Allí, pendiendo de los árboles se dejaba a los culpables para que sirvieran de escarmiento a los que trataran de seguir su ejemplo. Posteriormente el juez conoció de otras causas, como las de los rateros urbanos y los contrabandistas de bebidas al cohólicas, ${ }^{83}$ que no necesariamente concluían en la horca. Fue hasta entonces cuando se requirió de cárceles. La mayoría de los presos tenían dos formas de salir: por sus propios pies hacia la libertad 0 en medio de un impresionante espectáculo urbano hacia el tablado en donde se les daba muerte con la "mascada de hierro". En consecuencia, estos espacios no fueron concebidos para largas permanencias reformadoras.

En I8I2, las Cortes de Cádiz suprimieron el Tribunal de la Acordada y la horca pública. Así, el edificio, convertido en Cárcel General, tuvo que recibir a los detenidos en la cárcel de la Audiencia, que estaba alojada en el palacio de los virreyes. $\mathrm{C}$ on la Independencia se le transformó en $\mathrm{C}$ árcel $\mathrm{N}$ acional de la ex Acordada, recluyéndose en ella a todo tipo de delincuentes. $Y$ si bien el hacinamiento era uno de los aspectos que más se le cuestionaron entonces, debe considerarse que $\mathrm{G}$ arcía de Torres no la concibió para albergar a tal cantidad de personas por periodos tan largos.

En el edificio no sólo vivían los hombres y mujeres que pagaban cuentas a la justicia sino también el aparato administrativo: el juez, el alcaide, el teniente y ocho comisarios; a ellos se sumaba una importante población flotante integrada por vigilantes, tinterillos, familiares de los presos, caballerangos y un nutrido grupo de molenderas.

83. Cumplido, "La cárcel de la Acordada en M éxico. O rigen de esta prisión y su estado moral en la actualidad", en EI M osaico M exicano... , op. cit., p. I24. 
Por su parte, la penitenciaría sí fue planteada para recibir tanto a detenidos como a procesados; a hombres y mujeres; a léperos y notables, hasta ocupar sus 622 celdas individuales. ${ }^{84} \mathrm{M}$ ás las respectivas viviendas del subdirector, carcelero mayor, administrador y capellán; siete salones para los nuevos juzgados y ocho locutorios para desahogar el lógico incremento de visitantes.

El párroco de la Santa Vera C ruz ya no se ocuparía de la penitenciaría, ya que se iba a contar con un capellán de planta: así se rompía un primer vínculo con la vida de barrio.

\section{Los programas arquitectónicos}

En la Acordada la gran cantidad de habitaciones, salas y patios distribuidos en dos plantas pueden ser agrupados en once funciones: impartición de justicia, detención, reclusión, salud, culto religioso, almacenamiento y preparación de alimentos, vigilancia, servicios, bodegas, vivienda de funcionarios y sirvientes, más los asociados con el transporte, es decir, cocheras, caballerizas, pajar, aperos para las cabalgaduras y pesebres, indispensables en un cuerpo que se abocaba a la vigilancia de los caminos. Pese a las acusaciones decimonónicas, García de Torres sí consideró, en el primer nivel, una sala para detenidos independiente de los calabozos de los procesados; incluyó también, en el segundo, una enfermería y espacio para convalecientes.

Por su parte, D e la H idalga replanteó varias de las funciones, en principio la de vigilancia, esencia del panóptico: toda la zona de reclusión giraría en torno del gran salón de inspección central, desde donde el recluso debería sentir que era permanentemente observado. El vigilante podría controlar todo sin cambiar de punto de mira y, a un tiempo, cubrir la mitad del polígono sin cambiar de postura. ${ }^{85} \mathrm{El}$ "corredor de ronda interior" posibilitaba darle una vuelta completa al edificio en cuatro minutos. ${ }^{86}$

Además, en el segundo nivel del referido salón central, los domingos se correrían las cortinas develando la mesa del altar y todos los presos, desde sus celdas, participarían de la misa. Setenta y dos años antes García de Torres

84. D e la H idalga, op. cit., p. 9.

85. Bentham, El panóptico, op. cit., p. 87.

86. D e la Hidalga, op. cit., p. I3. 
164 HUGO ARCINIEGA

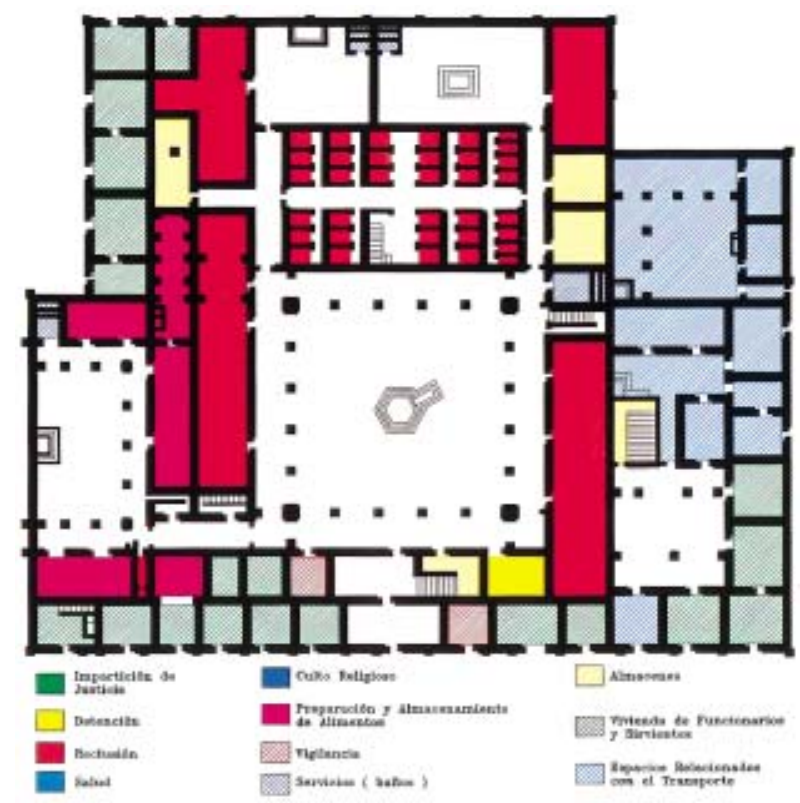

Figura 6. Casa y Cárceles de H ombres y M ujeres del Real Tribunal de la Acordada, estudio de áreas de actividad, primer nivel. Arquitecto J osé J oaquín García de Torres, 1776. Dibujo: Nahún Arturo.

colocó el altar en el centro de la nave de la capilla, diseñando una serie de muros, celosías y desniveles para que las diferentes clases de procesados no pudiesen reconocerse entre sí durante la celebración. De la arquitectura monacal, el veedor de arquitectura retomó los coros y las cratículas y si bien es cierto que hombres y mujeres tenían que desplazarse desde sus calabozos hasta el sacro recinto, lo es también que para cada sector propuso circulaciones que posibilitaban el acceso y la salida de forma independiente.

En un siglo en que las ciencias médicas impactaban en el urbanismo y la arquitectura, no se podía descuidar la "reforma física" de los reclusos; así que en su penitenciaría el arquitecto español proyectó ocho grandes jardines para que pudiesen ejercitar los músculos, "respirar el aire puro y contemplar el cielo y la naturaleza", ${ }^{87}$ siempre en silencio, soledad y bajo observación. El cuerpo ya no sería más blanco del castigo sino uno de los medios para modi- 


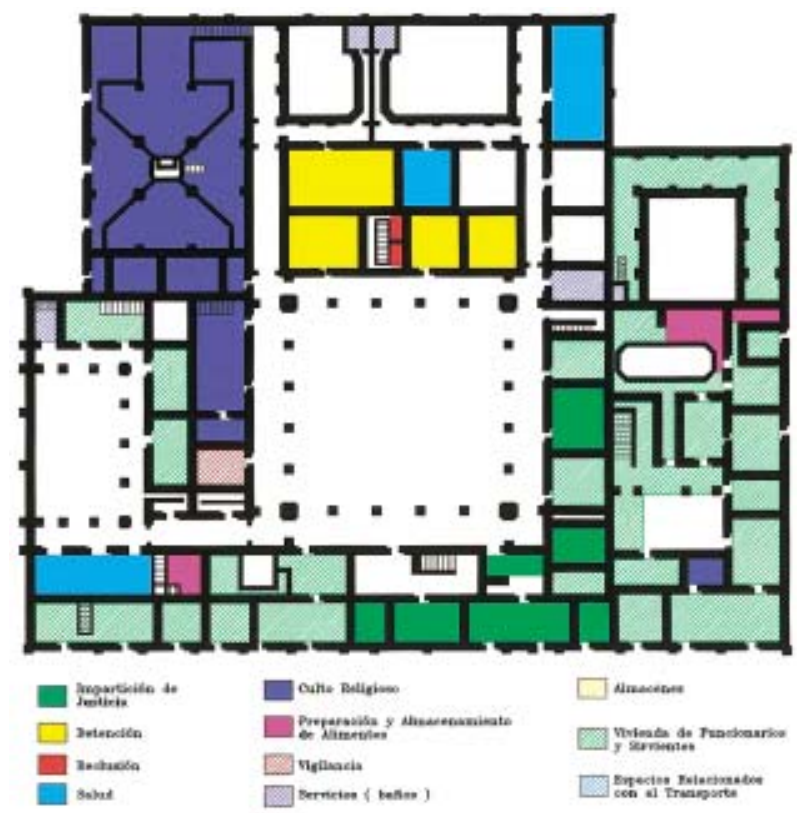

Figura 7. Casa y Cárceles de H ombres y M ujeres del Real Tribunal de la Acordada, estudio de áreas de actividad, segundo nivel. Arquitecto J osé J oaquín G arcía de Torres, I776. D ibujo: $\mathrm{N}$ ahún Arturo.

ficar el comportamiento criminal. La salud comenzaba con la higiene personal, por lo que los recién ingresados deberían bañarse, se les rasuraría todo el cabello e inmediatamente vestirían el uniforme a rayas, el sambenito del xix. Para los días siguientes se reservarían los baños de tina y tanque.

Si la ociosidad "es la madre de todos los vicios" entonces se debería mantener al reo en rehabilitación en constante actividad. El trabajo sería parte importante de la "reforma moral"; pero al proyectar bajo el sistema celular absoluto ${ }^{88} \mathrm{D}$ e la $\mathrm{H}$ idalga respondía a las expectativas de $\mathrm{M}$ ariano $\mathrm{O}$ tero pero no a las de los empresarios que pretendían aprovechar esa fuerza de trabajo en la producción industrial. En los talleres sólo se permitiría ocuparse en aquellos oficios artesanales que ya se poseyeran, dado que, para este arquitec-

88. "al dar yo la preferencia al sistema de Pennsylvania, recomendado también a la Junta Directiva de Cárceles por el Sr. O tero... " I bidem. 


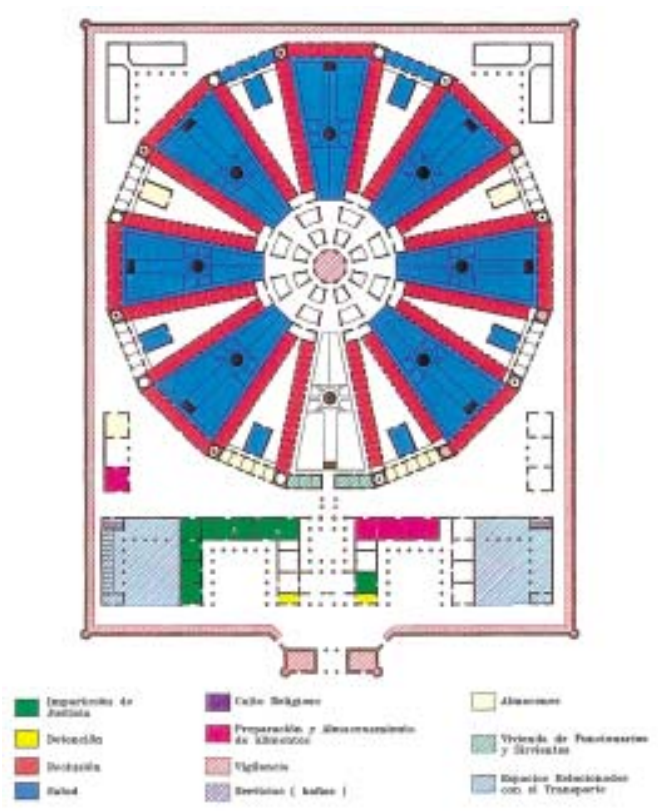

Figura 8. Penitenciaría General de la ciudad de M éxico, estudio de áreas de actividad, primer nivel. Arquitecto Lorenzo de la H idalga, I848. D ibujo: N ahún Arturo.

to, privar a un hombre de su trabajo era una de las mayores crueldades que se le podía infligir. ${ }^{89}$

En el programa arquitectónico de la penitenciaría aparecieron nuevos componentes: el cambio de una administración militar a una civil se expresaba en los recintos reservados a un administrador - despacho, estudio privado y casa. Durante su estancia en la ex Acordada, I gnacio Cumplido había recibido un trato preferencial al ser alojado en una accesoria deshabitada; pero esta reutilización de espacios no implica que García de Torres hubiese establecido otra diferenciación física que las de mujeres - hombres o bandidos- contrabandistas. Esta situación, en cambio, sí la marcó D e la H idalga, siguiendo la convocatoria, con las cuarenta y nueve celdas mayores destinadas a notables o para aquellos pensadores que, a través de la prensa, sacudieran a los regímenes en el poder.

89. Ibidem. 


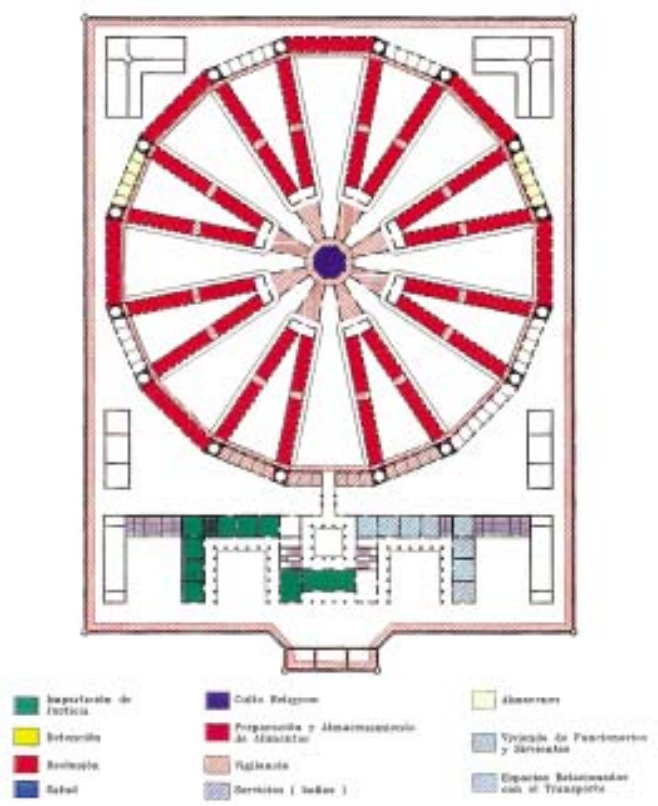

Figura 9. Penitenciaría G eneral de la ciudad de M éxico, estudio de áreas de actividad, segundo nivel. Arquitecto Lorenzo de la H idalga, 1848. D ibujo: $N$ ahún Arturo.

La cárcel captaba mediante sus seis patios aire, iluminación natural, calor y el agua de las lluvias que, durante el verano, refrescaba los interiores y lavaba los muros. En la penitenciaría, además de los dieciséis patios proyectados, se indican compartimentos para "caloríferos y ventiladores artificiales".

\section{Criterios estructurales}

Por analogía con la arquitectura de la época, supongo que la ex Acordada estuvo cimentada con zapatas corridas de piedra; sus muros levantados con la consabida mezcla de piedra, ladrillo y argamasa; y las cubiertas formadas de viguerías y terrados. En el caso de la penitenciaría, Cumplido no publicó las especificaciones constructivas por lo que ahora sólo podría adelantar que De la $\mathrm{H}$ idalga repetía constantemente que la arquitectura se reduce a dos princi- 
pios: convenance y économie. $9^{\circ}$ Estas ideas las tomó del Précis des leçons d'architecture de Jean $\mathrm{N}$ icolas Louis D urand, ${ }^{91}$ tratado que seguramente conoció durante su estancia en la École des Beaux-Arts de París, en la que siguió cursos bajo la dirección de Henri Labrouste..$^{92}$ La convenance incluía los conceptos de solidité, salubrité y comodité; al primero lo interpretó como la distribución uniforme del peso total del edificio sobre el suelo; y el adecuado "enlace" de los cimientos con los muros y de éstos con las cubiertas. En el mercado del Volador desarrolló un emparrillado de cedro para distribuir las cargas sobre las arcillas que conformaban el subsuelo. ${ }^{93}$ En la penitenciaría ubicó escaleras y caloríferos en los extremos de las crujías de servicio como "puntos de refuerzo". 94

\section{Los estilos}

De las portadas del convento de San Lorenzo de M éxico, Tovar escribió: "un severo estilo de transición entre el barroco, de líneas quebradas, y un cierto acento clasicista". 95

La cárcel de la Acordada era un edificio barroco sobrio o neóstilo; el acceso central estaba compuesto por elementos bien definidos: pilastras, capiteles, entablamento y friso. Las ondulaciones comenzaban en los roleos del frontón truncado, del que emergían las armas españolas, enmarcadas por las "líneas quebradas" del remate. Las placas ubicadas en ambos lados del portón mostraban en sus bordes intrincados diseños fitomorfos. El resto de los vanos mantenía la tradición de prolongar las jambas hasta las cornisas que señalaban los dos niveles y el coronamiento. Toda la fachada estaba modulada por pilastras que a nivel de la calle incidían en el rodapié provocando un efecto de movimiento. El recubrimiento de delgadas láminas de tezontle

90. G arcía Barragán, "Lorenzo de la H idalga”, en Santiago Sebastián, D el arte. H omenaje a Justino Fernández, op. cit., p. 215.

91. H anno-W alter Kruft, H istoria de la teoría de la arquitectura 2. D esde el siglo XIX hasta nuestros días, M adrid, Alianza Forma, I990, vol. 2, pp. 483-484.

92. M anuel Revilla, O bras. Biografías (artistas), M éxico, Imprenta de Victoriano Agüeros, I908, p. 28.

93. G arcía, op. cit., p. 215.

94. D e la H idalga, op. cit., p. Io.

95. Tovar, op. cit., p. 46. 
contrastaba en color y texturas con la cantera aplicada en los enmarcamientos y cornisas; para el rodapié se eligió otro tipo de piedra más oscuro.

Sobre la composición de los alzados, D e la H idalga opinaba: "las fachadas no son más que una consecuencia de la combinación horizontal o de la planta..." 96

Para resaltar el carácter administrativo del edificio que daría frente hacia la calzada del Ejido, lo trazó bajo las proporciones del toscano y dórico, pero aplicando este último con extrema sobriedad, es decir, suprimiendo los "adornos de talla". Pero esta mesura no obedecía solamente a los requerimientos de la convocatoria sino al principio de économie y al cuestionamiento que Durand hizo de la ornamentación arquitectónica, Ilamando la atención sobre la dependencia que se genera entre la nature des matériaux y las formas.97

M antuvo su acostumbrada jerarquización del acceso principal mediante pórticos delimitados simétricamente; el effet se lograría con la proyección de sombras detrás de las columnas (por eso en el Gran Teatro Santa Anna dio una distancia de dos intercolumnios desde el muro del fondo hasta el peristilo)..$^{98}$

Rompió la monotonía horizontal del paramento al remeterlo en cuatro secciones, generando con ello cuatro patios y creando un ritmo espacial de entrantes y salientes. Por otra parte, condujo la visual hacia el pórtico mediante el escalonamiento de los volúmenes, que culmina con la gran cúpula sobre el salón central. Es claro que, en este caso, D e la Hidalga proyectó, más que con elementos sobrepuestos a los muros, con los propios cuerpos sólidos.

Subordinando todo al eje de simetría romano,99 la planta académica de un edificio debía ser muestra de regularité y simplicité, lo que facilitaría su ejecución, abaratando los costos de construcción. Para cumplir con el principio de économie, $\mathrm{D}$ e la $\mathrm{H}$ idalga evitó en lo posible los muros curvos, las paredes de gran espesor y las cerraduras complicadas, y se preocupó por lograr circulaciones de servicio cómodas. ${ }^{\text {Ioo }}$

Rechazó categórico la aplicación del neogótico, neoegipcio y neohindú, a los que consideraba "la decadencia arquitectónica", en tanto que distorsionaban el carácter: "La mayor parte de estos edificios, más bien que de cárceles

96. D e la H idalga, op. cit., p. 9.

97. Kruft, op. cit., p. 484.

98. G arcía, op. cit., p. 213.

99. Sigfried Giedion, La arquitectura, fenómeno de transición (las tres edades del espacio en arquitectura), Barcelona, G ustavo Gili, 1975, p. 9I.

ıoo. D ela H idalga, op. cit., p. I7. 
tienen el carácter de fortalezas y castillos de la Edad M edia [... ] es evidente que una cárcel $[\ldots$... no puede tener el carácter de una fortaleza, porque su destino es diferente... "IоI

\section{La solución arquitectónica}

García de Torres partió de un patio central, rodeando las áreas de reclusión con las de vivienda, que sólo tenían acceso desde la calle, y las de preparación de alimentos. Desarrolló el programa en dos niveles: conservando la tradición de la planta noble, ubicó el tribunal, la capilla, la enfermería y la casa del juez en el superior.

De la H idalga separó las funciones, y de uno se amplió a un conjunto de edificios: administración de justicia, vivienda, preparación de alimentos, lavado y caballerizas integrarían el primer bloque paralelo al trazo de Ejido. La zona de reclusión sería "una combinación del sistema radiante con el circular, que proporciona la ventaja de cerrar el perímetro de todo el edificio [... ] por separado de la administración". 102 D e manera inconexa quedarían emplazados los almacenes y talleres.

En la transición espacial desde la calle hasta la zona de reclusión utilizó el esquema compositivo que ya había probado con éxito en el Teatro de Santa Anna: el cuerpo de guardia se encontraría varios metros remetido con respecto a una arbolada calzada del Ejido. D esde allí el visitante circularía por un pórtico, un vestíbulo, y un patio antes de encontrarse con el estrecho pasillo que uniría la administración con la penitenciaría. Lo que en el teatro era un recorrido que preparaba al individuo para los goces líricos, aquí conduciría al criminal hacia la soledad permanente.

\section{Relaciones con el contexto urbano inmediato}

La cárcel se integraba a la vida urbana a través del conjunto de accesorias que abrían sus puertas hacia las calzadas del Calvario y de la Acordada. Las proporciones de sus vanos no eran diferentes de las que podían verse en el resto 
de las calles de la ciudad. Sus vecinos: el H ospicio de Pobres, al oriente; los ejidos de la H orca, al sur y poniente; y la huerta de San D iego, al norte, no debieron representar, en un principio, problemas de convivencia. El edificio mismo constituía un mensaje moral, en piedra, para quienes prolongaban sus excursiones desde la Alameda hasta el Paseo N uevo; pero a partir de la segunda mitad del siglo xix, cuando aquel sector urbano se fue poblando, comenzaron las presiones para mover de allí el recinto de los presos, ya no considerado como una colindancia agradable.

D e haberse construido, lo que los vecinos del barrio de San Cosme hubieran visto de la nueva penitenciaría serían larguísimos lienzos de muro ciego, recorridos de cuando en cuando por los vigilantes: barreras visuales en forma de murallas. Un perfil que en nada convenía a los fraccionadores de los ejidos, que pretendían desarrollar allí zonas habitacionales de alto nivel. Con la venta de esas tierras, en I855, el ayuntamiento perdió el control sobre el desarrollo del Cuartel de Inválidos. El propio De la $\mathrm{H}$ idalga parece no haber contado con un plan integral para el lugar: en i85i edificó, en la esquina de Rosales y Ejido, una plaza de toros y un año más tarde llevaría hasta la glorieta de la Acordada, en la intersección de Paseo Nuevo y Calvario, la estatua de C arlos IV;iO3 con ello contribuyó a consolidar el carácter recreativo de aquella zona de la ciudad. Éstas fueron decisiones que, tal vez, no le tocó asumir a él, ${ }^{\text {I04 }}$ pero que se oponían rotundamente al aspecto severo y reformador de la edificación.

\section{Elementosiconográficos}

Las características externas de la Acordada y la disposición de sus accesorias hacían similar a este edificio con otros contemporáneos destinados para administración y salud. Para diferenciarlo, sobre el acceso principal se colocaron las armas españolas en razón de que el delito civil:

además de su víctima inmediata ataca al soberano; lo ataca personalmente ya que la ley vale por la voluntad del soberano [... ] El castigo de los crímenes [... ]

103. Tovar, op, cit., p. 174.

104. En i85s los ejidos de la H orca pasaron a ser propiedad de Francisco Somera y estuvieron considerados para su proyecto de colonia de los Arquitectos. 
DOI: http://dx.doi.org/10.22201/iie.18703062e.2000.76.1895

172

HUGO ARCINIEGA

implica la reparación del daño que se ha hecho a su reino, del desorden instaurado, del ejemplo dado [... ] pero implica también que el rey procura la venganza de una afrenta que ha sido hecha a su persona. ${ }^{\text {Ios }}$

Pero las armas no resultaban un distintivo suficientemente definitorio ya que se hallaban esculpidas en otras portadas; así que García de Torres le pidió al filipense José Rincón que compusiera tres octavas en donde se previniera de los suplicios que aguardaban al infractor de la ley del rey dentro del edificio, garantizando al "hombre justo" la seguridad de sus caudales. ${ }^{106}$ Luego las mandó reproducir en sendas lápidas, que colocó sobre la fachada principal.107

Tampoco se olvidó de la mitología clásica pues la fuente del patio mayor remataba con una escultura de la diosa Themis. ${ }^{108}$

De la Hidalga, a petición de 0 tero, colocaría en ambos lados de la administración las efigies de John H oward y Bentham. Pero aparte de éstas y de los órdenes arquitectónicos ya referidos, no se indica ninguna otra imagen, ni siquiera el escudo nacional. D espués de la guerra con Estados U nidos y en un momento de consolidación de la república, existía un vacío de poder que se manifiesta, junto a la austeridad requerida, en las limpias fachadas.

I05. Foucault, op. cit., p. 53 .

I06. García Cubas, El libro de mis recuerdos... , op. cit., p. 23 I.

I07. Estrofa de ocho versos de rima consonante:

"Inscripción i / Aquí la maldad gime aprisionada, / mientras la humanidad es atendida: / una por la justicia es castigada. / Y otra por la piedad es socorrida. / Pasajero que ves esta morada / Endereza los pasos de tu vida: / Pues la piedad que adentro hace favores, / N o impide a la justicia sus rigores."

"Inscripción II / Aquí en prisiones duras yace el vicio, / víctima a los suplicios destinada: / Y aquí a pesar del fraude y artificio, / resulta la verdad averiguada. / Pasajero respeta este edificio / Y procura evitar su triste entrada: / Pues cerrada una vez su dura puerta / sólo para el castigo se ve abierta."

"Inscripción III / Aquesta excelsa fábrica suntuosa, / D efensa es de las vidas y caudales: / Y su muralla fuerte y espaciosa, / Al público le impide muchos males. / Tú que miras su fachada hermosa, / Cuida como pasas sus umbrales: / Q ue aquí vive severa la justicia, / Y aquí muere oprimida la malicia." Angulo, op. cit., pp. I50-152.

Io8. "me dirigí al centro del patio, y acercándome a la fuente observé en su centro una estatua tan mutilada, que apenas se conocía haber tenido en su principio la forma humana; fijando en ella mi atención pregunté lo que representó en su origen, a lo cual se me satisfizo diciendo que era la diosa Themis... " Cumplido, op. cit., p. I29. 
La evidencia arqueológica

A nivel de superficie, la huella de ambos edificios ha quedado impresa en el sistema calle-manzana: las dimensiones de la Cárcel $\mathrm{N}$ acional de la ex Acordada pueden aproximarse dentro del área que delimitan, al norte, la avenida Benito Juárez; al sur, la calle de Artículo ${ }_{\text {I23; }}$ al oriente, Lucas Balderas, ${ }^{109}$ y al poniente Agustín de Iturbide. Las calles de Alexander von Humboldt y D onato Guerra muestran el proceso de crecimiento de la ciudad, así como la subdivisión de los antiguos solares novohispanos. Ambos cambios son propios de la transformación de la estructura urbana desarrollada durante la segunda mitad del siglo xix.

La penitenciaría, por su parte, generó dos calles nuevas: la del mismo nombre hoy José M aría Lafragua, y la de Inválidos, hoy Ignacio Luis Vallarta, que se unieron a la preexistente calzada del Ejido, hoy avenida de la República, y posteriormente a la de Las Artes que se corresponde con Antonio C aso. Vallarta fue ampliada durante este siglo perdiéndose buena parte de su paramento poniente y con la construcción de la plaza de la República se recortó el predio por el norte.

Al comparar los planos de la Acordada enviados al rey de España en $1782^{\text {IIO }}$ con la litografía publicada por Cumplido en ${ }^{\mathrm{I} 84 \mathrm{I}},{ }^{\mathrm{III}}$ resultan ya notorios los cambios exteriores: por efecto de la Independencia se han borrado las armas españolas; consecuencia de las luchas entre "escoceses y yorkinos" apareció un garitón sobre la fachada principal, tímido intento por resguardar a la Cárcel $\mathrm{N}$ acional de otro pronunciamiento como el de Lucas Balderas; y para la espera de los visitantes dos bancas de piedra custodiaban, entonces, el acceso central.

Entre i84i y i848 nuevos elementos se integraron al programa original: escuela, talleres, cuartel de policía y morgue, que seguramente modificaron la distribución interna del edificio. Ante la imposibilidad de transformarla con arreglo al sistema de vigilancia centralizada o panóptico, y a consecuencia de sus limitaciones en cuanto a capacidad de las áreas de reclusión, acabó

Io9. "el 30 de noviembre de i828 tomó parte en el pronunciamiento de La Acordada [... ] tal movimiento desconoce las elecciones por las que ha resultado presidente el ministro de guerra, M anuel Gómez Pedraza, y declara legítimo J efe de la N ación a Vicente Guerrero."

Cárdenas, op. cit., t. I, p. 153 .

iıo. Angulo, op. cit., p. 328.

III. Cumplido, op. cit., t.v, p. I23. 
por ser juzgada inadecuada como vehículo para aplicar la reforma penitenciaria de $M$ ariano 0 tero.

En i867, al dejar de cumplir su función carcelaria, se inició su proceso de destrucción. Como cuartel sobrevivió al gunos años más hasta que, entre i88o y $1883{ }^{112}$ al ser vendida a particulares, comenzó a ser demolida. La calle de Humboldt partió en dos el predio y ya para igos en su lugar se levantaban varias casas habitación.

H asta i85o el proyecto de la penitenciaría seguía viento en popa; Ignacio Cumplido veía realizada, sólo en parte, su iniciativa y se daba a la tarea, por encargo del ministerio de Fomento, Colonización, Industria y Comercio, de imprimir los planos y explicaciones de $\mathrm{D}$ e la $\mathrm{H}$ idalga.

El registro documental permite saber que hasta 1853 , antes de la vuelta al poder de Antonio López de Santa Anna, las obras de construcción de la pe nitenciaría no habían comenzado aún. ${ }^{113}$ Afirmar que desde abril de ese año hasta agosto de i855 - fecha en que Su Alteza Serenísima salió rumbo al exilio- no se avanzó en los trabajos debido únicamente a la falta de recursos es inexacto, ya que durante ese periodo se creó el ministerio de Fomento, la Administración $\mathrm{N}$ acional de Caminos y se mejoró la ruta que unía a M éxico con Cuernavaca. II4 Propongo que otras causas deben buscarse en el predominio conservador en el gabinete y en el desinterés que el veracruzano mostró por el proyecto. Tal parece que para ejercer la represión resultaban más convenientes los oscuros cal abozos que las utopías de una intelectualizada élite.

\section{Reflexiones finales}

La Acordada fue un edificio concebido con una fuerte vinculación al espacio urbano, tanto en lo físico como en lo funcional. De las octavas de José Rincón podemos inferir el efecto atemorizador que con su sola presencia pretendía imponer: en estas duras prisiones los "suplicios" arrancan la ver-

II2. Rivera, op. cit., p. 247.

II3. José M aría Lacunza, "sobre que se ponga en corriente la toma de agua que ha de disfrutar la penitenciaría como establecimiento público en razón de ir a comenzarse ya la obra de aquel edificio", I853 (АНЕAсм), Aguas. Edificios públicos, vol. 32, exp. 33, ff. I-4.

II4. Rafael F. M uñoz, Santa Anna, el dictador resplandeciente, M éxico, Fondo de Cultura Económica, 1996, p. 246. 
dad, los "rigores" hacen gemir y la "maldad" muere en la horca pública, "pues cerrada una vez su dura puerta sólo para el castigo se ve abierta".

Las áreas de vivienda y de preparación de alimentos cubrían a las de reclusión y el tras zaguán reducía la vista hacia el patio mayor. Así, desde la calle poco se podía saber de lo que ocurría dentro, y se desbordaba con ello la imaginación popular.

García de Torres contradice la terrible severidad de la lectura exterior con la capilla y sus diversas circulaciones y accesos, que protegían la identidad de los reclusos, así como con la enfermería y la sala de convalecientes, que cuidaban su vida, y con los "pulgueros", que resguardaban sus escasas pertenencias. La insalubridad era sólo un poco más acentuada que la que se padecía en las calles 0 en los barrios periféricos de la ciudad.

La forma de vida de por lo menos dos siglos quedó manifiesta en el tamaño, forma y asociación de los espacios; de esto son excelentes ejemplos las relaciones previstas entre los graneros, despensas, "piezas de molenderas", cocinas, patio y fuente; y por otro lado, pajar, caballerizas, pileta y pesebreras cubiertas con portal.

La penitenciaría desarrollaba su programa arquitectónico hacia el interior de un muro perimetral, que la convertía en una isla dentro de la estructura urbana; se cerraba a la tradición religiosa al romper nexos con las capillas e iglesias del barrio; se cerraba a la vida pública al suprimirse la horca; y se cerraba a la percepción del habitante promedio que reconocía el valor jerárquico de unas armas sobre el acceso principal. Sería doble motivo de orgullo y tranquilidad para una élite instruida que vería cómo la ciudad se equipaba con un elemento que habría de denotar "civilización y progreso" al ofrecer una alternativa reformadora para los delincuentes, y modernidad, al erigirse conforme al modelo panóptico.

En el criterio de ordenamiento de los espacios penitenciarios, las zonas de reclusión se superponen a todas las demás; la de impartición de justicia triplica su tamaño y las de vivienda quedan mimetizadas. Los edificios polifuncionales van cediendo su lugar ante la búsqueda del carácter como la definición y exaltación de la actividad principal.

Las críticas hechas a la Cárcel $\mathrm{N}$ acional de la ex Acordada por Cumplido, Condon y 0 tero fueron dirigidas más a la reutilización de los espacios, verificada por el propio hombre del xix, que a la disposición física planeada originalmente por José Joaquín G arcía de Torres. Esto sin dejar de considerar los prejuicios existentes sobre las instituciones virreinales y la necesidad de describir "terribles calabozos". 
A la luz de los proyectos presentados, podemos afirmar que el panopticón de Bentham se pretendió aplicar en M éxico bajo el tamiz norteamericano y en consecuencia desde i840, por lo menos, existía una pormenorizada observación de los avances que en el campo de la arquitectura alcanzaban nuestros belicosos vecinos. De Europa, las otras influencias que pesaron fueron $\mathrm{H}$ oward y Baltard.

D e la $\mathrm{H}$ idalga proyectó, en este caso, para un funcionario y no para una sociedad: descuidó las necesidades de los empresarios, los únicos capaces de rescatar su penitenciaría, al no establecer el esperado vínculo entre cárcel y fábrica y al intentar mantener un uso del espacio urbano que ya no se correspondía con las aspiraciones imperantes en la segunda mitad del siglo xix. En su búsqueda de la planta académica descuidó los requerimientos de las actividades cotidianas como, por ejemplo, el tamaño y la forma necesaria de las cocinas para alimentar a esa cantidad de presos.

Los espacios de castigo abandonaron las crujías, calabozos colectivos, en favor de la celda de aislamiento total: un nuevo intento por transformar a la sociedad corporativa, gremial, de hermandad y casta heredada del virreinato. El individuo aislado, separado del grupo que le daba fuerza, sin libertad de acción y bajo vigilancia permanente, sería la materia prima de una fábrica que ofrecería como producto final, a las élites, hombres dóciles para verificar el nuevo proyecto de nación. Para García Torres, hombre del siglo xvin, la cárcel era un espacio penitencial que preparaba al criminal para la muerte 0 el aislamiento social; para D e la H idalga y M usitu, hombre del siglo xix, "los presos [acabarían] por conformarse con su situación y [llegarían] a adquirir una resignación y obediencia maquinal". III

La explicación historiográfica inmediata para el abandono del proyecto de $\mathrm{D}$ e la $\mathrm{H}$ idal ga se encuentra siempre en las arcas públicas, lo cual es correcto. Pero, al considerar el traslado de los presos de la ex Acordada a Belén, o la continuidad de los mismos vicios en Lecumberri, parecería que en M éxico se prescindió, deliberadamente, de una verdadera reforma penitenciaria y se siguió necesitando el efecto atemorizador de la cárcel.\$ 
DOI: http://dx.doi.org/10.22201/iie.18703062e.2000.76.1895

LOS PALACIOS DE THEMIS

\section{Bibliografía}

Angulo Íñiguez, D iego, Planos de monumentos arquitectónicos de América y Filipinas existentes en el Archivo de Indias. Estudio de los planos y de su documentación, vol. I del catálogo y vol. I de láminas, España, U niversidad de Sevilla, I939.

Arciniega Ávila, H ugo Antonio, "El xIx, otro siglo de utopías", en Colonia T abacalera: varias lecturas sobre un patrimonio, M éxico, U niversidad Autónoma M etropolitana-Xochimilco, I994, pp. 38-88.

Baltard, Víctor, Architectonographie des prisons, ou parallèle des divers systèmes de distribution dont les prisons sont susceptibles, París, edición del autor, 1839, 35 pp.

Bentham, Jeremy, El panóptico, prólogo de M ichel Foucault, M éxico, Premiá, I989 (La N ave de los Locos), i93 pp.

Brenton, David le, Antropología del cuerpo y modernidad, 2a. edición, Buenos Aires, N ueva Visión, 1995, 249 pp.

Cárdenas de la Peña, Enrique, M il personajes en el M éxico del siglo XIX. I840-I870, M éxico, Banca Somex, 1979, t. II.

Díaz, Lilia, "El liberalismo militante", en Historia general de M éxico, za. edición, M éxico, EI Colegio de M éxico, 198I, t. 2, pp. 819-872.

Escalante G onzalbo, Fernando, Ciudadanosimaginarios, M éxico, El Colegio de M éxico, 1998, $294 \mathrm{pp}$.

Foucault, M ichel, Vigilar y castigar. N acimiento de la prisión, ı6a. edición, M éxico, Siglo XXI, I989 (N ueva C riminología y D erecho), 314 pp.

García Barragán, Elisa, "Lorenzo de la H idalga”, en D e arte H omenaje a Justino Fernández, M éxico, Universidad N acional Autónoma de M éxico, Instituto de Investigaciones Estéticas, 1977, pp. 203-218.

- - - " "El palacio de Lecumberri y su contexto arquitectónico", en Lecumberri: un palacio Ileno de historia, M éxico, Secretaría de Gobernación-Archivo General de la N ación, I994, pp. 45-62.

García Cubas, Antonio, El libro de mis recuerdos... , M éxico, Porrúa, 1986 (Biblioteca Porrúa, 86), $635 \mathrm{pp}$.

Giedion, Sigfried, La arquitectura, fenómeno de transición. (Las tres edades del espacio en arquitectura), Barcelona, Gustavo G ili, 1975 (Biblioteca de Arquitectura), 359 pp.

$\mathrm{H}$ idalga, Lorenzo de la, Paralelo y proyecto de penitenciaría aprobado por la Junta de Cárceles, M éxico, Imprenta de I gnacio Cumplido, I850, 23 pp.

Katzman, Israel, Arquitectura del siglo Xıx en M éxico, 2a. edición, M éxico, Trillas, I993, $397 \mathrm{pp}$.

K ruft, $\mathrm{H}$ anno-W alter, $\mathrm{H}$ istoria de la teoría de la arquitectura, 2. D esde el siglo xıx hasta nuestros días, M adrid, Alianza Forma, 1990, 866 pp.

M aclachlan, Colín M ., La justicia criminal del siglo xviII en M éxico. Un estudio sobre el Tribunal de la Acordada, M éxico, Secretaría de Educación Pública, 1976 (SepSetentas, 240), ıо $\mathrm{pp}$. 
DOI: http://dx.doi.org/10.22201/iie.18703062e.2000.76.1895

178

HUGO ARCINIEGA

M ayer, Brantz, M éxico: lo que fue y lo que es, M éxico, Fondo de Cultura Económica, I953 (Biblioteca Americana, Serie Viajeros).

M ellado, Guillermo, Belén por dentro y por fuera, M éxico, Ediciones Botas, 1959 (Cuadernos "Criminalia", 2I), $204 \mathrm{pp}$.

M uñoz F., Rafael, Santa Anna, el dictador resplandeciente, 4a. edición, M éxico, Fondo de Cultura Económica, 1996 (Colección Popular, 247), 274 pp.

Pavarini, M assimo, "La invención de la penitenciaría: la experiencia de los Estados U nidos de América en la primera mitad del siglo xix", en Cárcel y fábrica. Los orígenes del sistema penitenciario (siglos XVI-XIX), M éxico, Siglo XXI, I980 (N ueva Criminología y D erecho), pp. $133-233$.

Perrot, M ichele, "El inspector Bentham”, en El panóptico, M éxico, Premiá, 1989 (La N ave de los Locos), pp. I45-193.

Revilla, Federico, D iccionario de iconografía, M adrid, C átedra, 1990 (Arte), 403 pp.

Revilla, M anuel, 0 bras. Biografías (artistas), M éxico, Victoriano Agüeros, 1908, t. I, 412 pp.

Rivera Cambas, $M$ anuel, M éxico pintoresco, artístico y monumental... , M éxico, Ediciones del Valle de M éxico, 1974, t. I, 249 pp.

Rueda Smithers, Salvador, EI diablo de Semana Santa. El discurso político y el orden social en la ciudad de M éxico en I850, M éxico, Instituto N acional de Antropología e H istoria, I99I (Colección de D ivulgación), 322 pp.

Summerson, John, El lenguaje clásico de la arquitectura. De L. B. Alberti a Le Corbusier, Barcelona, Gustavo G ili, 1984 (C olección Punto y Línea), I72 pp.

Tovar de Teresa, Guillermo, Repertorio de artistas en M éxico. Artes plásticas y decorativas, Singapur, Espejo de 0 bsidiana, 1996, t. II.

Valle-Arizpe, Artemio de, Por la vieja calzada de T lacopan, M éxico, D iana, 1980, 423 pp.

Vázquez, Josefina Zoraida, "Los primeros tropiezos", en H istoria general de M éxico, za. edición, M éxico, El Colegio de M éxico, 198I, t. 2, pp. 735-803.

Fuentes

AHEACM: Archivo H istórico del ex Ayuntamiento de la Ciudad de M éxico

H emerografía

El M osaico M exicano o colección de amenidades curiosas e instructivas, t. v, M éxico, I84I.

Siglo xıx. Revista de H istoria, núm. I2, M éxico, 1992. 